\title{
Is clostridium difficile associated with relapse of inflammatory bowel disease? results from a retrospective and prospective cohort study in the Netherlands
}

Citation for published version (APA):

Masclee, G. M., Penders, J., Jonkers, D. M. A. E., Wolffs, P. F. G., \& Pierik, M. J. (2013). Is clostridium difficile associated with relapse of inflammatory bowel disease? results from a retrospective and prospective cohort study in the Netherlands. Inflammatory Bowel Diseases, 19(10), 2125-2131. https://doi.org/10.1097/MIB.0b013e318297d222

Document status and date:

Published: 01/09/2013

DOI:

10.1097/MIB.0b013e318297d222

Document Version:

Publisher's PDF, also known as Version of record

\section{Document license:}

Taverne

\section{Please check the document version of this publication:}

- A submitted manuscript is the version of the article upon submission and before peer-review. There can be important differences between the submitted version and the official published version of record. People interested in the research are advised to contact the author for the final version of the publication, or visit the DOI to the publisher's website.

- The final author version and the galley proof are versions of the publication after peer review.

- The final published version features the final layout of the paper including the volume, issue and page numbers.

Link to publication

\footnotetext{
General rights rights.

- You may freely distribute the URL identifying the publication in the public portal. please follow below link for the End User Agreement:

www.umlib.nl/taverne-license

Take down policy

If you believe that this document breaches copyright please contact us at:

repository@maastrichtuniversity.nl

providing details and we will investigate your claim.
}

Copyright and moral rights for the publications made accessible in the public portal are retained by the authors and/or other copyright owners and it is a condition of accessing publications that users recognise and abide by the legal requirements associated with these

- Users may download and print one copy of any publication from the public portal for the purpose of private study or research.

- You may not further distribute the material or use it for any profit-making activity or commercial gain

If the publication is distributed under the terms of Article 25fa of the Dutch Copyright Act, indicated by the "Taverne" license above, 


\title{
Is Clostridium difficile Associated With Relapse of Inflammatory Bowel Disease? Results From a Retrospective and Prospective Cohort Study in the Netherlands
}

\author{
Gwen M. C. Masclee, MD, ${ }^{*}+$ John Penders, PhD, ${ }^{t, \neq}$ Daisy M. A. E. Jonkers, PhD, ${ }^{*, \neq}$ Petra F. G. Wolffs, PhD, ${ }^{+, \neq}$ \\ and Marie J. Pierik, MD, PhD ${ }^{*} \neq$
}

\begin{abstract}
Background: Although Clostridium difficile may be associated with exacerbations in inflammatory bowel diseases (IBD), prospective studies identifying the role of $C$. difficile in disease activity are currently lacking. We examined the prevalence of $C$. difficile in feces of (1) symptomatic IBD patients retrospectively and (2) consecutive outpatients in relation to disease activity prospectively.

Methods: From adult IBD patients with increase of symptoms, fecal samples collected between November 2010 and 2011 were tested for $C$. difficile, Salmonella, Shigella, Yersinia, and Campylobacter spp. Within a prospective IBD cohort, fecal samples, clinical data, and disease activity scores were collected every 3 months and during relapses. Baseline samples from all subjects (170 Crohn's disease, 116 ulcerative colitis) and additional samples from patients with changing disease activity during follow-up (57 Crohn's disease, 31 ulcerative colitis) were tested for $C$. difficile and when positive for toxin $\mathrm{A}$ and $\mathrm{B}$ genes by quantitative polymerase chain reaction.

Results: From 104 symptomatic patients, 139 fecal samples were analyzed. Toxinogenic C. difficile and Campylobacter jejuni were detected in 3.6\% and $1.8 \%$. In the prospective cohort, $C$. difficile prevalence at baseline was significantly different neither between ulcerative colitis (3.4\%) and Crohn's disease patients $(5.9 \%)$ nor between active $(8.2 \%)$ and quiescent $(3.3 \%)$ disease. In multivariable analysis, $C$. difficile was not associated with disease activity, disease subtype, gender, antibiotic, and immunosuppressive therapy. Clostridium difficile was also not associated with disease activity within patients with changing disease activity over time $(P=0.45)$.
\end{abstract}

Conclusions: We found a low prevalence of $C$. difficile, and our findings indicate that $C$. difficile is not a common trigger for exacerbations of IBD in clinical practice in the Netherlands.

(Inflamm Bowel Dis 2013;19:2125-2131)

Key Words: Clostridium difficile, inflammatory bowel disease, exacerbation, bacterial pathogen, real-time polymerase chain reaction

$\mathrm{T}$ he chronic inflammatory bowel diseases (IBD), Crohn's disease (CD), and ulcerative colitis (UC) are characterized by flares and episodes of remission. Especially, relapses are associated with high health care costs and a decreased quality of life. ${ }^{1-3}$ Up to $10 \%$ of IBD flares are reported to be the result of microbial pathogen invasion. ${ }^{4}$ In the last decade, several studies have focused on the possible association between Clostridium difficile and IBD..$^{5-7}$

Clostridium difficile is a gram-positive anaerobic sporeforming bacterium. Colonization of the intestinal tract occurs via the fecal-oral route and is facilitated by disruption of the

Received for publication March 28, 2013; Accepted April 18, 2013.

From the *Division of Gastroenterology and Hepatology, Department of Internal Medicine; ${ }^{\dagger}$ Department of Medical Microbiology; and ${ }^{\ddagger}$ School for Nutrition, Toxicology and Metabolism (NUTRIM), Maastricht University Medical Center, Maastricht, the Netherlands

The authors have no conflicts of interest to disclose.

Reprints: Marie J. Pierik, MD, PhD, Division Gastroenterology and Hepatology, Department of Internal Medicine, Maastricht University Medical Center, PO Box 5800, 6202 AZ Maastricht, the Netherlands (e-mail: m.pierik@mumc.nl).

Copyright (C) 2013 Crohn's \& Colitis Foundation of America, Inc.

DOI 10.1097/MIB.0b013e318297d222

Published online 17 July 2013. commensal intestinal microbiota for instance due to antimicrobial therapy. The organism is capable of producing exotoxins responsible for symptomatic Clostridium difficile infection (CDI): toxin A, a powerful enterotoxin, and toxin B, a potent cytotoxin. Both toxins bind to receptors on intestinal epithelial cells and can cause disruption of the actin cytoskeleton and impairment of tight junctions. Furthermore, they are cytotoxic and lead to the production of proinflammatory cytokines. ${ }^{8}$ Subsequently, this may result in a large spectrum of clinical symptoms ranging from watery diarrhea to pseudomembranous colitis. ${ }^{9}$ In the past decade, the incidence of $C$. difficile associated diarrhea among the general population has increased significantly, partially due to the emergence of a more virulent strain, which is more resistant to antibiotic therapy. ${ }^{10}$ Asymptomatic carriage of $C$. difficile is found in $20 \%$ to $50 \%$ of adult hospitalized patients. ${ }^{11}$

Although the increase in CDI is even more pronounced in IBD patients than among the general population, ${ }^{5,7}$ prevalences reported for IBD vary widely. Clostridium difficile was found in $3 \%$ to $24 \%$ of UC patients with active disease ${ }^{7,12-14}$ and in $4 \%$ to $14 \%$ of CD patients with active disease. ${ }^{12,14,15}$ In addition, Clayton et $\mathrm{al}^{16}$ showed that $C$. difficile was present in $9.4 \%$ of UC and in 
$6.9 \%$ of $\mathrm{CD}$ patients in remission on stable doses of aminosalicylates for at least 6 months. Particularly, high incidences of CDI (up to $47 \%$ ) among hospitalized IBD patients are reported in studies from the United States. ${ }^{5,7,17}$ These findings contrast with a recent German study reporting a prevalence of only $3.9 \%$ in hospitalized IBD patients. ${ }^{12}$ The differences in prevalence may be related to the more restricted policy of antibiotic use in Northern European countries compared with the United States. ${ }^{18,19}$ Recent antibiotic use was noted in only $20 \%$ of $C$. difficile-infected IBD patients in the German study ${ }^{12}$ but in up to $60 \%$ of the patients in an American study. ${ }^{5}$ Besides geographic localization, differences in study setting and population may contribute to the variation in prevalence. The majority of studies is performed in inpatients and report high prevalences, ${ }^{20-24}$ which is in line with hospitalization being a risk factor. Furthermore, it has to be taken into account that most of the current studies are performed retrospectively. ${ }^{6,7,23,25,26}$ This may result in either underestimation or overestimation of CDI due to miscoding, inclusion of inpatients and outpatients, and availability of information of only selected patient groups, in whom CDI was assessed for clinical reasons. ${ }^{27}$ In addition, the outpatient setting and hospital setting seems to be an important source of acquisition for IBD patients, ${ }^{20,28}$ and asymptomatic carriage has not been investigated in the retrospective studies.

The prevalence of $C$. difficile in IBD outpatients and the association with disease activity remains unclear, especially when considering patients with a low frequency of antibiotic use due to a restrictive antibiotic police, as is common practice in the Netherlands. ${ }^{19}$

The aim of the present study was (1) to evaluate retrospectively the prevalence of toxinogenic $C$. difficile in fecal samples from IBD patients who had been collected routinely because of increase in symptoms and (2) to evaluate prospectively the presence of nontoxinogenic and toxinogenic $C$. difficile in relation to disease activity in a consecutive cohort of adult IBD outpatients. In addition, we identified risk factors for $C$. difficile colonization in the outpatient setting.

\section{METHODS}

\section{Retrospective Study}

At the Maastricht University Medical Center, fecal specimens of IBD patients presenting with worsening of symptoms (i.e., diarrhea, bloody stools, or abdominal pain), indicating a potential relapse, are routinely sent to the laboratory of Medical Microbiology for analysis of the presence of enteric bacterial pathogens. Toxinogenic C. difficile, Salmonella spp., Shigella spp., Yersinia spp., and Campylobacter spp. are analyzed by standard microbiological methods.

All results from fecal specimens of adult IBD patients (age $\geq 18$ years) sent to the laboratory of Medical Microbiology between November 2010 and November 2011 were extracted electronically from the laboratory system and reviewed for presence of enteric bacterial pathogens. Concomitant medication use within the 6 months before fecal analysis was obtained from the hospital pharmacy and local pharmacies. Fecal samples cultured within 3 weeks of a previous sample as control of successful antibiotic treatment were excluded from further analysis.

\section{Prospective Study}

\section{Patients}

Between August 2009 and November 2010, consecutive IBD patients visiting the outpatient IBD clinic of a combined secondary and tertiary hospital (Maastricht University Medical Center) were included in a prospective cohort study with 1-year follow-up after inclusion. The design of this prospective study and the standardized follow-up of patients have been described previously. ${ }^{29}$ The diagnosis of CD or UC was based on endoscopic, histological, and/or radiological findings. Patients visited the hospital every 3 months and at time of relapse, during which fecal samples and clinical data were collected using standardized sampling and registration protocols.

Patients were provided with a small plastic box (Fisher Scientific, Landsmeer, the Netherlands) and instructed to collect a fecal sample on the evening before or the morning of each visit and to store the sample at $4^{\circ} \mathrm{C}$. On arrival at the laboratory, undiluted feces was frozen at $-80^{\circ} \mathrm{C}$ within 24 hours after defecation. Fecal samples from the inclusion visit of all patients were used for further analyses in the present study (i.e., baseline cohort). Furthermore, from a subgroup of patients with changing disease activity during follow-up, a second sample was evaluated (i.e., follow-up cohort).

Data of concomitant medication use, smoking status (current smoker, quit smoking within or over 6 months, never smoked), body mass index, disease location, disease duration, and phenotype ([non-] penetrating [non-] and structuring, according to the Vienna classification ${ }^{30}$ ) were extracted from the computerbased medical registration databases. Disease activity was scored by the validated Harvey-Bradshaw index for CD patients, ${ }^{31}$ the Simple Clinical Colitis Activity Index for UC patients, ${ }^{32}$ and the Pouchitis Disease Activity Index for UC patients with a pouch. ${ }^{33}$ A period of 6 months before fecal sampling was reviewed for antibiotic exposure using the hospital and local pharmacy registers. If no information was available confirming either the use or nonuse of antibiotics, data were considered missing and not included in the analyses.

\section{Detection of Clostridium difficile}

Extraction and purification of total DNA was performed with the PSP Spin Stool DNA kit (Invitek GmbH, Berlin, Germany) according to the manufacturer's instructions. DNA was subsequently stored at $-20^{\circ} \mathrm{C}$ until further analysis.

The quality of DNA extraction was ensured by the isolation of positive ( $C$. difficile ATCC 9689) and negative controls. In addition, before the extraction of nucleic acids, all samples were spiked with murine cytomegalovirus RNA, which was used as an extraction and amplification control. 
Amplification reactions for the detection of $C$. difficile were performed in a $25 \mu \mathrm{L}$ volume, containing $1 \times(12.5 \mu \mathrm{L})$ TaqMan universal PCR master mix, ${ }^{34} 900 \mathrm{nM}$ forward primer, $900 \mathrm{nM}$ reverse primer, $200 \mathrm{nM}$ probe, $8.6 \mu \mathrm{L}$ nuclease free water, and finally $2 \mu \mathrm{L}$ of purified target DNA. The amplification program consisted of 2 minutes at $50^{\circ} \mathrm{C}$, followed by 42 cycles of 15 seconds at $95^{\circ} \mathrm{C}$ and 1 minute at $60^{\circ} \mathrm{C}$. Primers and probes used in the current study have been used and validated previously. ${ }^{35,36}$ Samples positive for $C$. difficile were subsequently analyzed for the presence of C. difficile toxin A gene $(t c d A)$ and toxin B gene $(t c d B)$. Amplification reactions for $t c d A$ and $t c d B$ were performed in the same manner as described above.

\section{Statistical Analysis}

Chi-square test or Fisher's exact test when appropriate was used to compare dichotomous variables between subgroups of patients. Univariable and multivariable logistic regression analyses were performed for the identification of risk factors for $C$. difficile. We included disease subtype (CD or UC); disease activity (active disease or remission); gender; age; immunosuppressive therapy (corticosteroids, methotrexate, and/or thiopurins), including the number of immunosuppressive agents; and anti-tumor necrosis alpha therapy. McNemar's test was used to examine the association between disease activity and $C$. difficile detection within the group of subjects of whom both a fecal sample during active disease and remission were available (follow-up cohort). Statistical analyses were performed using SPSS, version 18.0. Statistical significance was defined as a $P$ value $<0.05$.

\section{Ethical Considerations}

The study was approved by the Medical Ethics Committee of the Maastricht University Medical Center, Maastricht, and written informed consent was obtained from all patients.

\section{RESULTS}

\section{Retrospective Study}

During 1 year, 138 fecal samples from 104 symptomatic IBD patients (69 CD, $35 \mathrm{UC}$ ) were routinely sent to the laboratory of Medical Microbiology. In 79 patients $(76 \%)$, only 1 fecal sample was analyzed. In 16 patients $(15.4 \%), 8$ patients $(7.7 \%)$, and 1 patient $(1.0 \%)$, a total number of 2,3 , and 4 samples with at least 3-week interval between sampling, respectively, were analyzed. Mean age of the patients was 44.5 years (SD 17.4), and 55\% were female.

Toxinogenic $C$. difficile was detected in $3.6 \%$ of analyzed samples (Figure 1) and did not differ significantly between CD and UC patients. Campylobacter jejuni was present in 1.9\% of samples, whereas Salmonella spp., Shigella spp., or Yersinia spp. were not detected.

\section{Prospective Study}

\section{Patients}

Overall, 323 patients were included in the consecutive IBD study cohort. From 286 patients, a baseline fecal sample was

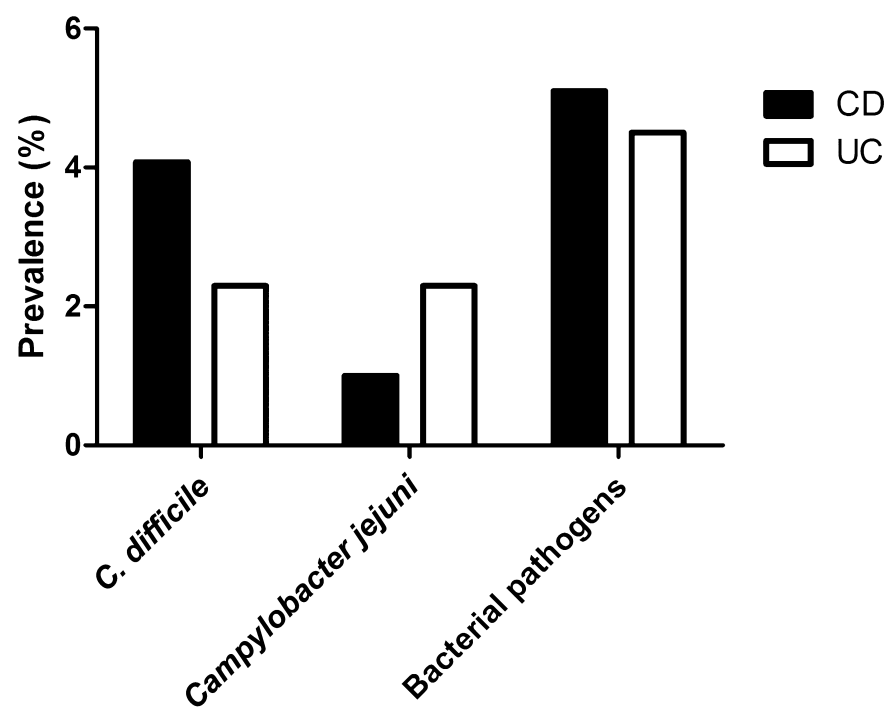

FIGURE 1. Prevalence of enteric bacterial pathogens in fecal samples of symptomatic CD and UC patients routinely sent to the laboratory of Medical Microbiology. Bacterial pathogens include toxinogenic Clostridium difficile, Salmonella spp., Shigella spp., Yersinia spp., and Campylobacter spp.

available (baseline cohort). Patient characteristics of the baseline cohort are shown in Table 1. Mean age at baseline was 46.2 years (SD 15.2 years), and mean disease duration was 12.4 years (SD 9.9 years). CD and UC were diagnosed in 59\% and $41 \%$ (including $15 \%$ with an ileal-anal pouch) of the study population, respectively. Active disease was present in 85 patients $(30 \%)$ and was comparable in CD (33\%) versus UC $(25 \%)$ patients $(P=0.15)$. The proportion of UC patients with pancolitis, left-sided colitis, and proctitis among those with active disease was $45 \%, 52 \%$, and $3 \%$, respectively. Information on prior antibiotic use was available for 193 patients. A total of 88 subjects had a change in disease activity in the 1-year follow-up and were included in the follow-up cohort.

\section{Baseline Cohort}

Overall, $C$. difficile was found in $4.9 \%$ of fecal samples. Clostridium difficile detection at baseline was significantly different neither in UC $(3.4 \%)$ compared with CD patients $(5.9 \%)(P=$ 0.41 ) (Figure 2 ) nor in patients with active disease (8.2\%) versus those in remission $(3.5 \%)(P=0.09)$. Of the 14 samples positive for C. difficile, $12.5 \%$ were $t c d A+/ t c d B+, 18.8 \%$ were $t c d A-/ t c d B+$, and the remaining $68.7 \%$ were negative for both toxins. Of the 14 patients with a positive $C$. difficile sample, 10 patients ( $8 \mathrm{CD}, 2 \mathrm{UC}$ ) were on immunosuppressive therapy, whereas 2 patients were on aminosalicylate therapy only and 2 patients did not receive maintenance therapy at all at time of $C$. difficile detection.

As no significant difference in $C$. difficile prevalence was found between $\mathrm{CD}$ and $\mathrm{UC}$, the logistic regression was performed on the total IBD population (Table 2). Although a statistically significant association between $C$. difficile and age was found in the univariable analysis (odds ratio $0.95 ; 95 \%$ confidence interval, 
TABLE 1. Characteristics of IBD Patients $(n=286)$ From the Prospective Cohort at Baseline

\begin{tabular}{|c|c|c|c|}
\hline & $\begin{array}{c}\mathrm{CD}(\mathrm{n}=170) \\
\mathrm{n}(\%)\end{array}$ & $\begin{array}{c}\mathrm{UC}(\mathrm{n}=116) \\
\mathrm{n}(\%)\end{array}$ & $P$ \\
\hline Male & $60(35.3)$ & $62(53.4)$ & $<0.01$ \\
\hline Mean age (SD), yrs & $44.0(15.0)$ & $49.4(14.9)$ & $<0.01$ \\
\hline Active disease & $56(32.9)$ & $29(25.0)$ & 0.15 \\
\hline Mean disease duration (SD), yrs & $12.2(10.7)$ & $12.5(8.6)$ & 0.80 \\
\hline \multicolumn{4}{|l|}{ Disease phenotype } \\
\hline $\begin{array}{l}\text { Nonpenetrating, } \\
\text { nonstricturing }\end{array}$ & $118(69.4)$ & - & - \\
\hline Stricturing & $29(17.1)$ & - & 一 \\
\hline Penetrating & $16(9.4)$ & - & - \\
\hline Stricturing and penetrating & $7(4.1)$ & - & 一 \\
\hline \multicolumn{4}{|l|}{ Disease location } \\
\hline Colon & $38(22.4)$ & - & - \\
\hline Small bowel only & $48(28.2)$ & - & - \\
\hline Ileocolonic & $84(49.4)$ & - & - \\
\hline Medication use & $144(84.7)$ & $105(90.5)$ & 0.15 \\
\hline Immunosuppressive therapy $^{a}$ & $124(72.9)$ & $53(45.7)$ & $<0.001$ \\
\hline Thiopurins & $60(35.3)$ & $30(25.9)$ & 0.09 \\
\hline Methotrexate & $9(5.3)$ & $4(3.4)$ & 0.57 \\
\hline Anti-TNF-alpha therapy & $75(44.1)$ & $24(20.7)$ & $<0.001$ \\
\hline Corticosteroids & $25(14.7)$ & $10(8.6)$ & 0.12 \\
\hline \multicolumn{4}{|l|}{ Aminosalicylates } \\
\hline Systemically & $33(19.4)$ & $61(52.6)$ & $<0.001$ \\
\hline Locally & $2(1.2)$ & $18(15.5)$ & $<0.001$ \\
\hline Immunosuppressive agents & & & $<0.001$ \\
\hline None & $46(27.1)$ & $63(54.3)$ & \\
\hline 1 & $86(50.6)$ & $39(33.6)$ & \\
\hline$\geq 2$ & $38(22.4)$ & $14(12.1)$ & \\
\hline Previous $\mathrm{AB}$ use $(\leq 6 \mathrm{mo})$ & & & 0.28 \\
\hline Yes & $28(16.5)$ & $12(10.3)$ & \\
\hline No & $86(50.6)$ & $67(57.8)$ & \\
\hline Missing & $56(32.9)$ & 37 (31.9) & \\
\hline
\end{tabular}

${ }^{\mathrm{a}}$ Combination of corticosteroids, methotrexate, and/or thiopurins.

$\mathrm{AB}$, antibiotic; Anti-TNF-alpha, anti-tumor necrosis factor alpha.

$0.91-0.99 ; P=0.013)$, this association did not remain statistically significant in the multivariable analyses. Clostridium difficile was not associated with disease subtype, disease activity, gender, antibiotic therapy, or immunosuppressive therapy.

\section{Follow-up Cohort}

Of the 88 patients in the follow-up cohort, 39 patients $(27$ $\mathrm{CD}$ and $12 \mathrm{UC}$ ) changed from inactive toward active disease and 49 patients (30 CD and $19 \mathrm{UC}$ ) changed from active toward inactive disease. The mean time between subsequent sampling was $110 \pm 71$ and $153 \pm 87$ days, respectively.

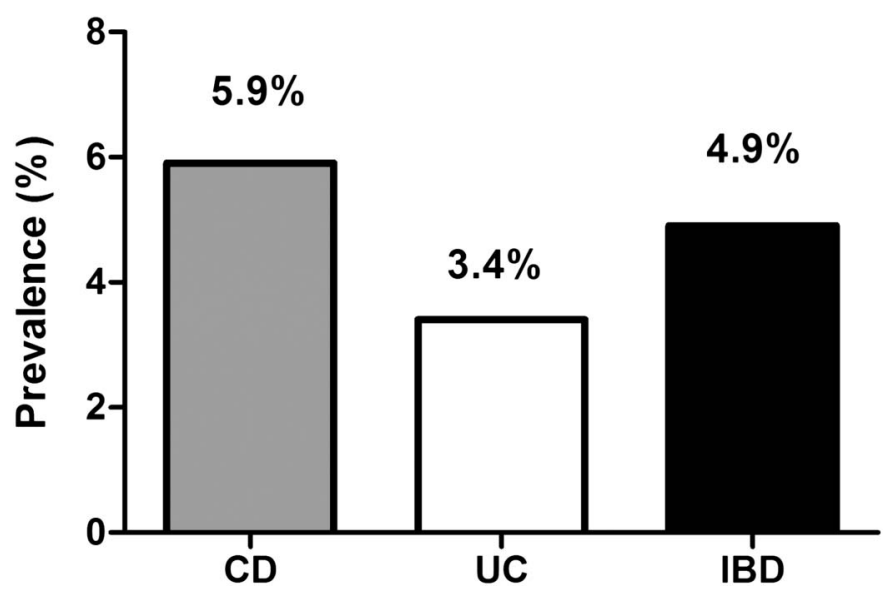

FIGURE 2. Prevalence of Clostridium difficile in fecal samples of the prospective cohort at baseline. IBD, inflammatory bowel disease patients overall.

In this follow-up cohort, 13 samples were positive for $C$. difficile. Of these 13 samples positive for $C$. difficile, 2 samples were $t c d A+/ t c d B+, 2$ samples were $t c d A-/ t c d B+$, and the remaining 9 samples were negative for both toxins.

Three patients had 2 consecutive samples positive for $C$. difficile. From those patients, 2 ( $1 \mathrm{CD}$ and $1 \mathrm{UC}$ patient) had a clinical course changing from active disease to remission with time between samples of 104 and 75 days, respectively. Only the UC patient was treated with ciprofloxacin before the first positive sample. The third patient (CD) changed from remission to active disease with 28 days between sampling. In all 3 patients, toxin positivity was only found in the baseline samples, being $t c d A+/$ $t c d B+$ for the UC patient and $t c d A-/ t c d B+$ for the CD patients.

Analysis of $C$. difficile within subjects of the follow-up cohort over time showed no significant difference with regard to changing disease activity $(P=0.45)$.

\section{DISCUSSION}

In this study, we evaluated the prevalence of fecal toxinogenic $C$. difficile not only retrospectively in IBD patients presenting with an increase in symptoms but also prospectively among consecutive IBD outpatients. A low prevalence of nontoxinogenic and toxinogenic $C$. difficile was found in fecal samples from IBD patients routinely taken because of increase in symptoms and in a prospective cohort of adult IBD outpatients in daily clinical practice. Clostridium difficile was not associated with disease activity, and no risk factors for $C$. difficile colonization could be identified.

First, we retrospectively reviewed the results from all fecal samples routinely sent to the laboratory of Medical Microbiology. According to local clinical guidelines, feces of IBD patients presenting with an increase in symptoms pointing to relapse of disease are analyzed for the presence of common gastrointestinal bacterial pathogens. Toxin-producing $C$. difficile comprised the majority of detected bacterial pathogens in fecal samples - in 
TABLE 2. Multivariable Analysis for Identification of Risk Factors for Clostridium difficile in the Baseline Cohort $(\mathrm{n}=286)$

\begin{tabular}{|c|c|c|c|}
\hline & ORcrude $(95 \% \mathrm{CI})$ & ORadj $(95 \% \mathrm{CI})$ & $P$ \\
\hline \multicolumn{4}{|l|}{ Disease subtype } \\
\hline $\mathrm{CD}$ & 1.00 & 1.00 & - \\
\hline UC & $0.57(0.18-1.87)$ & $0.83(0.24-2.93)$ & 0.772 \\
\hline \multicolumn{4}{|l|}{ Disease activity } \\
\hline Remission & 1.00 & 1.00 & - \\
\hline Active disease & $2.49(0.85-7.33)$ & $2.26(0.72-7.10)$ & 0.163 \\
\hline Age, yrs & $0.95(0.91-0.99)$ & $0.96(0.93-1.00)$ & 0.060 \\
\hline \multicolumn{4}{|l|}{ Gender } \\
\hline Male & 1.00 & 1.00 & - \\
\hline Female & $0.99(0.34-2.94)$ & $0.74(0.24-2.34)$ & 0.611 \\
\hline \multicolumn{4}{|c|}{$\begin{array}{l}\text { Immunosuppressive } \\
\text { therapy* }\end{array}$} \\
\hline No & 1.00 & 1.00 & - \\
\hline Yes & $1.31(0.45-3.82)$ & $1.14(0.37-3.45)$ & 0.821 \\
\hline \multicolumn{4}{|l|}{$\begin{array}{l}\text { Anti-TNF-alpha } \\
\text { therapy }\end{array}$} \\
\hline No & 1.00 & 1.00 & - \\
\hline Yes & $2.65(0.89-7.87)$ & $1.60(0.50-5.15)$ & 0.433 \\
\hline \multicolumn{4}{|l|}{ Antibiotic use $^{\mathrm{a}}$} \\
\hline No & 1.00 & 1.00 & - \\
\hline Yes & $1.29(0.25-6.65)$ & $0.69(0.10-4.66)$ & 0.705 \\
\hline \multicolumn{4}{|c|}{$\begin{array}{l}\text { Immunosuppressive } \\
\text { agents }^{\mathrm{b}}\end{array}$} \\
\hline No & 1.00 & 1.00 & - \\
\hline 1 & $1.32(0.36-4.82)$ & $0.84(0.22-3.25)$ & 0.797 \\
\hline$\geq 2$ & $2.19(0.53-9.12)$ & $1.21(0.26-5.57)$ & 0.807 \\
\hline \multicolumn{4}{|c|}{$\begin{array}{l}\text { Any immunosuppresive } \\
\text { agent use }\end{array}$} \\
\hline No & 1.00 & 1.00 & - \\
\hline Yes & $1.57(0.48-5.14)$ & $0.95(0.27-3.34)$ & 0.931 \\
\hline
\end{tabular}

${ }^{\mathrm{a} O n l y}$ subjects included in logistic regression analyses when data were available (193/ 286: $67.5 \%$ ).

${ }^{\mathrm{b}}$ Combination of corticosteroids, methotrexate, and/or thiopurins.

${ }^{\mathrm{c} C}$ Combination of corticosteroids, methotrexate, thiopurins, and/or anti-TNF-alpha therapy. Anti-TNF-alpha, anti-tumor necrosis factor alpha; OR, odds ratio; 95\% CI, 95\% confidence interval.

accordance with literature- ${ }^{4,6,37}$ but still was found in only $3.6 \%$ of the samples. Only limited information on recent antibiotic use was available and therefore not included in further analyses.

Because of the limitations of a retrospective analysis, we subsequently, prospectively, assessed the presence of $C$. difficile in relation to disease activity in an unselected consecutive cohort of IBD outpatients using molecular techniques. Our finding that C. difficile prevalence was low in IBD outpatients, not only in the retrospective $(3.6 \%)$ but also in the prospective analysis $(4.9 \%)$, is in line with several previous studies. ${ }^{4,7,12,37,38}$ All but one of these studies were performed in European countries. Although we used a more sensitive method for detection of $C$. difficile and toxins compared with the study performed in Germany, ${ }^{12}$ the prevalence in that study is comparable to ours as we prospectively included consecutive outpatients instead of retrospectively including inpatients. However, higher prevalences have also been reported. ${ }^{14,15,17,23,24}$ It is important to note that the latter studies have mainly been performed in the United States. In these studies, no information on severity of disease and antibiotic use was available, ${ }^{7,23,24,26}$ but antibiotic use is generally known to be more frequent in the United States. ${ }^{39}$ This is in contrast to the Netherlands, where antibiotics are much less commonly used. ${ }^{18,19}$

Furthermore, the current prospective study was performed in a combined secondary and tertiary hospital, thereby including a representative population of the full spectrum of IBD patients instead of merely high-risk patients in other studies. ${ }^{12,20}$ Yet the prevalence of $C$. difficile we observed in IBD patients was still higher than among the general population in the Netherlands as a recent study among Dutch patients with community-onset diarrhea, for which microbiological diagnostics were requested, reported a prevalence of only $1.5 \% .{ }^{40}$ Several studies have reported an increasing incidence of CDI in IBD, but it has to be taken into account that this may also be affected by an increased clinical awareness and more frequent testing of $C$. difficile in recent years. ${ }^{27}$

Although Clayton et $\mathrm{al}^{16}$ have pointed to the presence of $C$. difficile during quiescent phase of IBD, others have reported that C. difficile tends to be more frequent during active disease. ${ }^{13,26}$ We also observed this trend, but the difference was not statistically significant. As a subgroup of patients in our study had changing disease activity during follow-up, additional fecal samples were analyzed to explore the ability of $C$. difficile as trigger of a relapse in IBD. In this unique group of patients, we were not able to show an association between disease activity and $C$. difficile. However, it should be taken into account that the absence of such an association might result from small numbers of patients changing toward active disease (i.e., 39 patients).

In the present study, toxinogenic $C$. difficile was rarely observed as both toxin $\mathrm{A}(t c d A)$ and toxin $\mathrm{B}(t c d B)$ genes were found in only $31 \%$ of $C$. difficile positive samples. Up to now, it is controversial which toxin is more crucial for pathogenicity. Yet it has become clear in recent years that both toxins can independently result in an infection. ${ }^{41}$

Although IBD patients in general are considered susceptible to acquire CDI, especially UC patients tend to be at high risk due to colonic involvement of inflammation..$^{5,14,15,23,24,26}$ We could not confirm this observation in our outpatient IBD cohort. Furthermore, we were not able to identify risk factors for $C$. difficile by multivariable analysis. However, this was not unexpected based on the small number of positive samples, and the low prevalence of $C$. difficile negatively influences the power to detect risk factors for colonization as presented in our multivariable analyses.

Information on prior antibiotic use was not available for $32 \%$ of the patients in the prospective cohort. However, it should be noted that in the Netherlands, overall antibiotic use is low due 
to a very restrictive antibiotic prescription policy. ${ }^{18,19}$ The latter in combination with the low number of $C$. difficile positive samples can explain the lack of identifying antibiotic use as a risk factor.

Strength of the current prospective study is that fecal samples were available from a large cohort of unselected consecutive IBD patients representing daily clinical practice. In a subgroup that underwent changes in disease activity during follow-up, additional fecal samples were analyzed, thus enabling to explore the ability of $C$. difficile in triggering relapses of IBD. However, we acknowledge the following limitations of the study. First, the duration of relapse was not taken into account. We have minimized this influence, by analyzing the prevalence of C. difficile in both active and inactive disease and the potential of $C$. difficile to trigger active disease by using the prospective follow-up cohort. Second, we cannot exclude those patients who have had symptoms due to a gastrointestinal infection before attending the clinic. However, patients experiencing gastrointestinal symptoms, which might be attributable to an exacerbation, are instructed to contact our clinic for further diagnostics and eventual adjustment of therapy. Patients usually visit the outpatient clinic within 2 weeks after onset of the first symptoms.

\section{CONCLUSIONS}

A low prevalence of $C$. difficile was found not only in the fecal samples from IBD patients who had been taken routinely because of increase in symptoms but also in a prospective cohort of adult IBD outpatients reflecting daily clinical practice. Clostridium difficile was not associated with disease activity, and no risk factors for $C$. difficile were identified. Our findings indicate that $C$. difficile is not a common trigger for relapse in IBD in daily clinical practice in the Netherlands.

\section{REFERENCES}

1. Bassi A, Dodd S, Williamson P, et al. Cost of illness of inflammatory bowel disease in the UK: a single centre retrospective study. Gut. 2004; 53:1471-1478.

2. Stark R, Konig HH, Leidl R. Costs of inflammatory bowel disease in Germany. Pharmacoeconomics. 2006;24:797-814.

3. Bokemeyer B, Hardt J, Huppe D, et al. Clinical status, psychosocial impairments, medical treatment and health care costs for patients with inflammatory bowel disease (IBD) in Germany: an online IBD registry. J Crohns Colitis. 2013;7:355-368.

4. Mylonaki M, Langmead L, Pantes A, et al. Enteric infection in relapse of inflammatory bowel disease: importance of microbiological examination of stool. Eur J Gastroenterol Hepatol. 2004;16:775-778.

5. Issa M, Vijayapal A, Graham MB, et al. Impact of Clostridium difficile on inflammatory bowel disease. Clin Gastroenterol Hepatol. 2007;5:345-351.

6. Meyer AM, Ramzan NN, Loftus EV Jr, et al. The diagnostic yield of stool pathogen studies during relapses of inflammatory bowel disease. $J$ Clin Gastroenterol. 2004;38:772-775.

7. Rodemann JF, Dubberke ER, Reske KA, et al. Incidence of Clostridium difficile infection in inflammatory bowel disease. Clin Gastroenterol Hepatol. 2007;5:339-344.

8. Hodges K, Gill R. Infectious diarrhea: cellular and molecular mechanisms. Gut Microbes. 2010;1:4-21.

9. Bartlett JG, Chang TW, Gurwith M, et al. Antibiotic-associated pseudomembranous colitis due to toxin-producing clostridia. $N$ Engl $J$ Med. 1978;298:531-534.
10. Lessa FC, Gould CV, McDonald LC. Current status of Clostridium diffcile infection epidemiology. Clin Infect Dis. 2012;55:65-70.

11. Riggs MM, Sethi AK, Zabarsky TF, et al. Asymptomatic carriers are a potential source for transmission of epidemic and nonepidemic Clostridium difficile strains among long-term care facility residents. Clin Infect Dis. 2007;45:992-998.

12. Ott C, Girlich C, Klebl F, et al. Low risk of Clostridium difficile infections in hospitalized patients with inflammatory bowel disease in a German tertiary referral center. Digestion. 2011;84:187-192.

13. Trnka YM, LaMont JT. Association of Clostridium difficile toxin with symptomatic relapse of chronic inflammatory bowel disease. Gastroenterology. 1981;80:693-696.

14. Bolton RP, Sherriff RJ, Read AE. Clostridium difficile associated diarrhoea: a role in inflammatory bowel disease? Lancet. 1980;1:383-384.

15. Meyers S, Mayer L, Bottone E, et al. Occurrence of Clostridium difficile toxin during the course of inflammatory bowel disease. Gastroenterology. 1981;80:697-670.

16. Clayton EM, Rea MC, Shanahan F, et al. The vexed relationship between Clostridium difficile and inflammatory bowel disease: an assessment of carriage in an outpatient setting among patients in remission. Am J Gastroenterol. 2009;104:1162-1169.

17. Jodorkovsky D, Young Y, Abreu MT. Clinical outcomes of patients with ulcerative colitis and co-existing Clostridium difficile infection. Dig Dis Sci. 2010;55:415-420.

18. Goossens H. Antibiotic consumption and link to resistance. Clin Microbiol Infect. 2009;15:12-15.

19. Goossens H, Ferech M, Vander Stichele R, et al. Outpatient antibiotic use in Europe and association with resistance: a cross-national database study. Lancet. 2005:365:579-587.

20. Bossuyt P, Verhaegen J, Van Assche G, et al. Increasing incidence of Clostridium difficile-associated diarrhea in inflammatory bowel disease. J Crohns Colitis. 2009;3:4-7.

21. Greenfield C, Aguilar Ramirez JR, Pounder RE, et al. Clostridium difficile and inflammatory bowel disease. Gut. 1983;24:713-717.

22. Rolny P, Järnerot G, Möllby R. Occurrence of Clostridium difficile toxin in inflammatory bowel disease. Scand J Gastroenterol. 1983;18:61-64.

23. Nguyen GC, Kaplan GG, Harris ML, et al. A national survey of the prevalence and impact of Clostridium difficile infection among hospitalized inflammatory bowel disease patients. Am J Gastroenterol. 2008;103: $1443-1450$

24. Ananthakrishnan AN, McGinley EL, Saeian K, et al. Temporal trends in disease outcomes related to Clostridium difficile infection in patients with inflammatory bowel disease. Inflamm Bowel Dis. 2011;17:976-983.

25. Kariv R, Navaneethan U, Venkatesh PG, et al. Impact of Clostridium difficile infection in patients with ulcerative colitis. J Crohns Colitis. 2011;5:34-40.

26. Ananthakrishnan AN, McGinley EL, Binion DG. Excess hospitalisation burden associated with Clostridium difficile in patients with inflammatory bowel disease. Gut. 2008;57:205-210.

27. Goodhand JR, Alazawi W, Rampton DS. Systematic review: Clostridium difficile and inflammatory bowel disease. Aliment Pharmacol Ther. 2011; 33:428-441.

28. Berg AM, Kelly CP, Farraye FA. Clostridium difficile infection in the inflammatory bowel disease patients. Inflamm Bowel Dis. 2013;19:194-204.

29. Masclee GM, Penders J, Pierik M, et al. Enteropathogenic viruses: triggers for exacerbation in IBD? A prospective cohort study using real-time quantitative polymerase chain reaction. Inflamm Bowel Dis. 2013;19:124-131.

30. Gasche C, Scholmerich J, Brynskov J, et al. A simple classification of Crohn's disease: report of the Working Party for the World Congresses of Gastroenterology, Vienna 1998. Inflamm Bowel Dis. 2000;6:8-15.

31. Sandborn WJ, Feagan BG, Hanauer SB, et al. A review of activity indices and efficacy end points for clinical trials of medical therapy in adults with Crohn's disease. Gastroenterology. 2002;122:512-530.

32. D'Haens G, Sandborn WJ, Feagan BG, et al. A review of activity indices and efficacy end points for clinical trials of medical therapy in adults with ulcerative colitis. Gastroenterology. 2007;132:763-786.

33. Sandborn WJ, Tremaine WJ, Batts KP, et al. Pouchitis after ileal pouchanal anastomosis: a pouchitis disease activity index. Mayo Clinic Proc. 1994;69:409-415.

34. Heim A, CE, Harste G, et al. Rapid and quantitative detection of human adenovirus DNA by real-time PCR. J Med Virol. 2003;70:228-239. 
35. Belanger SD, Boissinot M, Clairoux N, et al. Rapid detection of Clostridium difficile in feces by real-time PCR. J Clin Microbiol. 2003;41: 730-734.

36. Penders J, Vink C, Driessen C, et al. Quantification of Bifidobacterium spp., Escherichia coli and Clostridium difficile in faecal samples of breastfed and formula-fed infants by real-time PCR. FEMS Microbiol Lett. 2005;243:141-147.

37. Antonelli E, Baldoni M, Giovenali P, et al. Intestinal superinfections in patients with inflammatory bowel diseases. J Crohns Colitis. 2012;6: 154-159.
38. Brown WJ, Hudson MJ, Patrick S, et al. Search for enteric microbial pathogens in patients with ulcerative colitis. Digestion. 1992;53:121-128.

39. van Buul LW, van der Steen JT, Veenhuizen RB, et al. Antibiotic use and resistance in long term care facilities. J Am Med Dir Assoc. 2012;13: 568.e1-e13.

40. Bauer MP, Veenendaal D, Verhoef L, et al. Clinical and microbiological characteristics of community-onset Clostridium difficile infection in the Netherlands. Clin Microbiol Infect. 2009;15:1087-1092.

41. Lyras D, O'Connor JD, Howarth PM. Toxin B is essential for virulence of Clostridium difficile infection. Nature. 2009;458:1176-1179. 